\title{
Sputter Deposition of Ferrite Films and Application for High Density Rigid Disk Media in Contact Mode
}

\author{
M. Naoe, N. Matsushita, K. Noma and S. Nakagawa \\ Department of Physical Electronics, Tokyo Institute of Technology, 2-12-1 O-okayama, Meguro, Tokyo \\ 152, Japan
}

\begin{abstract}
Co-Zn ferrite and BaM ferrite films were deposited on silicon wafer disks with thermally oxidized surface layer without annealing process, and their read/write characteristics in contact mode have been investigated by using a MIG and $\mathrm{Mn}-\mathrm{Zn}$ ferrite head with gap length of 0.2-0.4 $\mu \mathrm{m}$. The highest linear recording density $\mathrm{D}_{50}$ of $\mathrm{Co}$-Zn ferrite and Ba ferrite films were 105 and $190 \mathrm{kFRPI}$, respectively. Clear dipulse was observed for isolated wave form of $\mathrm{Ba}$ ferrite disks and then dipuise ratio was 0.65 . It was concluded that the $\mathrm{Co}-\mathrm{Zn}$ ferrite films and $\mathrm{Ba}$ ferrite films have high potential as an isotropic and a perpendicular recording layer, respectively, in contact recording mode at ultra-high density
\end{abstract}

\section{INTRODUCTION}

The spacing between magnetic head and rigid disk media has being decreased with increasing of recording density and a contact recording media have to be investigated for achieving ultra-high recording density above $20 \mathrm{Gbit} / \mathrm{inch}^{2}$. The sputtered ferrite films seem to be superior candidates for contact recording layer because of their excellent chemical stability, high corrosion resistance, well wear pass durability and so on. Moreover, the media noise of ferrite disks are low and almost constant even at high recording density, it would be a superior merit to conventional Co-based alloy disks[1]. Especially both films of a spinel type of $\mathrm{Co}-\mathrm{Zn}$ ferrite films with (111) orientation and a magnetoplumbite type of $\mathrm{Ba}(\mathrm{BaM})$ ferrite films with c-axis orientation seemed to be very suitable for isotropic[2] and perpendicular magnetic recording layer, respectively, because they possessed excellent surface smoothness and highly dense cross-sectional morphology as well as excellent magnetic properties. Therefore, in this study, Co-Zn ferrite and BaM ferrite films were deposited on silicon wafer disks with thermally oxidized surface layer without psot-annealing process, and their read/write characteristics in contact mode have been investigated by using a MIG and Mn-Zn ferrite head.

\section{EXPERIMENTAL PROCEDURE}

Prior to the fabrication of specimen disks, several $\mathrm{Co}-\mathrm{Zn}$ ferrite $\left(\mathrm{Co}_{0.5} \mathrm{Zn}_{0.5} \mathrm{Fe}_{2.0} \mathrm{O}_{4.0}\right)$ and $\mathrm{BaM}$ ferrite $\left(\mathrm{Ba}_{1.0} \mathrm{Fe}_{12.0} \mathrm{O}_{19.0}\right)$ films were deposited by a facing targets sputtering(FTS) apparatus and a conventional RF diode sputtering apparatus, respectively, to optimize the surface smoothness, crystallographic characteristics and magnetic properties. Various deposition conditions for $\mathrm{Co}-\mathrm{Zn}$ ferrite and $\mathrm{BaM}$ ferrite films were shown in Table 1. The FTS system can realize damage-free deposition and there is no discrepancy of film composition between the target and the deposited films[3]. The plates which have the same stoichiometric composition of $\mathrm{Co}_{0.5} \mathrm{Zn}_{0.5} \mathrm{Fe}_{2.0} \mathrm{O}_{\mathrm{x}}$ were used

Table 1 : Deposition Conditions

\begin{tabular}{|c|c|c|}
\hline & Co- $Z n$ ferrite & BaM ferrite \\
\hline $\begin{array}{l}\text { Sputtering } \\
\text { Apparatus }\end{array}$ & Facing Targets & RF Diode \\
\hline $\begin{array}{l}\text { Target } \\
\text { Composition }\end{array}$ & $\mathrm{Co}_{0.5} \mathrm{Zn}_{0.5} \mathrm{Fe}_{2.0} \mathrm{O}_{\mathrm{x}}$ & $\mathrm{Ba}_{1.7} \mathrm{Fe}_{12.0} \mathrm{O}_{\mathrm{x}}$ \\
\hline $\begin{array}{l}\text { Ar gas pressure } \\
\mathrm{O}_{2} \text { gas pressure }\end{array}$ & $\begin{array}{l}1.98 \text { mTorr } \\
0.02\end{array}$ & ${ }_{0.002-2.0}^{3.68}$ mTorr \\
\hline $\begin{array}{l}\text { Substrate } \\
\text { Temperature }\end{array}$ & $90-500^{\circ} \mathrm{C}$ & $620^{\circ} \mathrm{C}$ \\
\hline Film Thickness & $200 \mathrm{~nm}$ & $200 \mathrm{~nm}$ \\
\hline $\begin{array}{l}\text { Substrate-target } \\
\text { distance }\end{array}$ & $\begin{array}{c}\text { substrate } \\
\text { target } \\
\end{array}$ & $\begin{array}{l}35-77 \mathrm{~mm} \\
\text { target }\end{array}$ \\
\hline
\end{tabular}


as the targets. On the other hand, since there is sexious plasma damage to surface of the growing film in a conventional RF diode sputtering system and $\mathrm{Ba}$ content is likely to be insufficient compared with stoichiometric composition of BaM ferrite $\left(\mathrm{Ba}_{1.0} \mathrm{Fe}_{12.0} \mathrm{O}_{19.0}\right)[4]$, the target with $\mathrm{Ba}$ enriched composition of $\mathrm{Ba}_{1.7} \mathrm{Fe}_{12.0} \mathrm{O}_{\mathrm{x}}$ was used. The substrate temperature $\mathrm{T}_{5}$ measured at substrate surface using thermocouple was varied in the range from 90 to $500^{\circ} \mathrm{C}$ for the deposition of Co- $\mathrm{Zn}$ ferrite films. On the other hand, the dependences of crystallographic characteristics and surface morphology on the distance between target and substrate $d_{t-s}$ and the partial oxygen gas pressure $P_{O_{2}}$ were investigated for the deposition of BaM ferrite films. Film thickness of both ferrite films was set at about $200 \mathrm{~nm}$. A silicon wafer chips and 2 inch disks with thermally oxidized surface layer were used as substrates.

The surface texture and cross-section morphology were observed by scanning electron microscopy (SEM). The crystallographic characteristics, such as the full width of half maximum $\Delta \theta_{50}$ and the quality factor for the c-axis orientation $\mathrm{f}_{\mathrm{c}}$, were calculated on $\mathrm{X}$-ray diffraction diagrams $(\mathrm{XRD})$, and magnetic characteristics such as the saturation magnetization $4 \pi \mathrm{M}_{\mathrm{S}}$ and the in-plane and perpendicular coercivities $H_{c / /}$ and $H_{c_{\perp}}$ were determined from the $M_{/ /}-H_{/ /}$and $M_{\perp}-H_{\perp}$ hysteresis loops, respectively, which were measured by using a vibrating sample magnetometer (VSM).

\section{RESULTS AND DISCUSSION}

\section{$3.1 \mathrm{Co}-\mathrm{Zn}$ ferrite films}

$\mathrm{Co}-\mathrm{Zn}$ ferrite film deposited at $\mathrm{T}_{\mathrm{s}}$ of $90^{\circ} \mathrm{C}$ revealed a flat surface and uniform morphology as shown in Fig. 1 and it was composed of crystallites with (111) orientation. This diffraction intensity of (111) increased with increase of $\mathrm{T}_{s}$ up to $250^{\circ} \mathrm{C}$. Since the easy and hard axes of spinel ferrite crystallite with $\mathrm{Co}$ ions are $\langle 100\rangle$ and $<111\rangle$, respectively, and $<100\rangle$ are distributed in a circular cone whose generation line canted at an angle of $35.3^{\circ}$ to the film plane, magnetization vector $\mathbf{M}$ seemed to be oriented isotropically in $\mathrm{Co}-\mathrm{Zn}$ ferrite film with (111) orientation as shown in Fig.2. Figure 3 shows typical hysteresis loops measured in in-plane and perpendicular direction and they revealed almost the same shape due to isotropic orientation of magnetization vector $\mathbf{M}$.

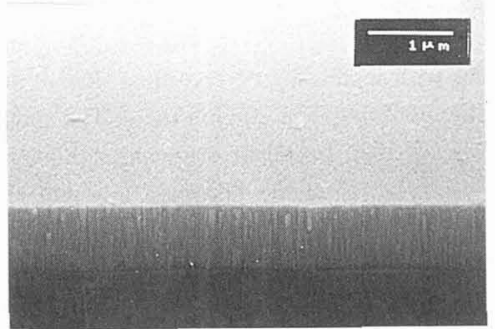

Fig.1 SEM photograph of Co-Zn ferrite film deposited at $\mathrm{T}_{\mathrm{S}}$ of $90^{\circ} \mathrm{C}$

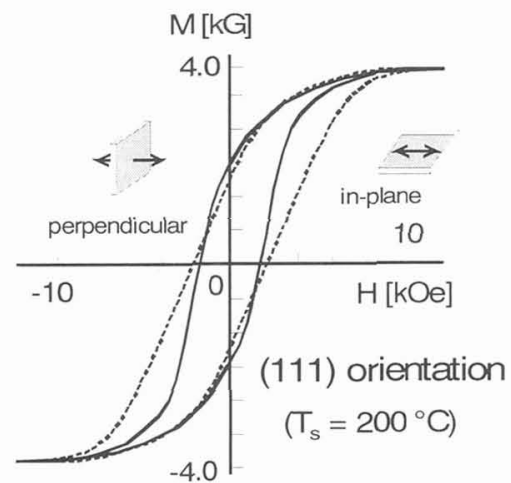

Fig.3 Typical hysteresis loops of Co-Zn ferrite film measured in in-plane and perpendicular directions.

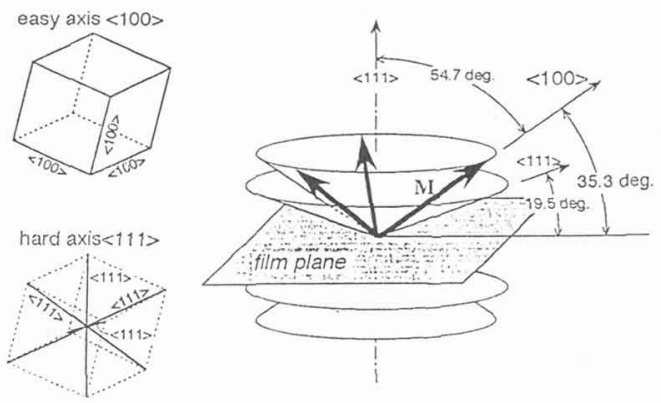

Fig.2 Magnetization vectors $\mathbf{M}$ of (111) oriented $\mathrm{Co}-\mathrm{Zn}$ ferrite crystallite.

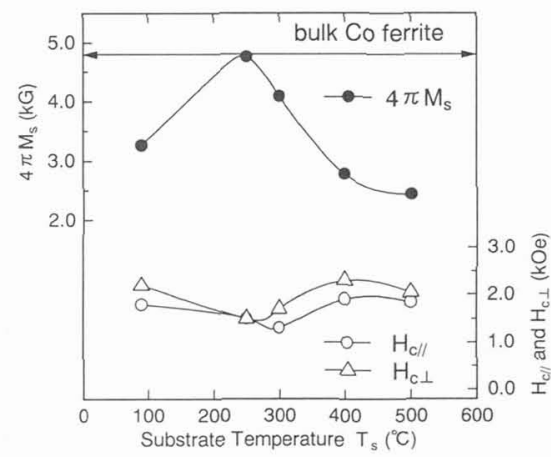

Fig.4 $T_{s}$ dependences of $4 \pi \mathrm{M}_{s}$ and $\mathrm{H}_{\mathrm{c} / /}$ and $\mathrm{H}_{\mathrm{c}_{\perp}}$ of Co-Zn ferrite film 
The maximum $4 \pi \mathrm{M}_{\mathrm{s}}$ of $4.8 \mathrm{kG}$ was obtained at $\mathrm{T}_{\mathrm{s}}$ of $250^{\circ} \mathrm{C}$ and it was almost equal to that of bulk Co ferrite as shown in Fig.4. The films in specimen disk was deposited at $T_{s}$ of $200^{\circ} \mathrm{C}$ and $4 \pi \mathrm{M}_{\mathrm{s}}$ and $\mathrm{H}_{\mathrm{c}}$ were estimated to be as large as $4.0 \mathrm{kG}$ and to be as moderately high as about $2.0 \mathrm{kOe}$, respectively.

Since Co-Zn ferrite films with (111) orientation possessed a flat surface and strong adhesion to disk substrate as well as sufficient hardness, the read/write characteristics of the specimen magnetic disks were evaluated without protective and lubricant layers. A MIG type head with gap length of $0.27 \mu \mathrm{m}$ was used for evaluating read/write characteristics, where the coil turn number and relative velocity were 31 and $2.3 \mathrm{~m} / \mathrm{s}$, respectively. Although actual flying height has not been measured, it was estimated at the value less than $300 \AA$. Figure 5 shows the dependences of output voltage on linear density. The normalized output has a 'shoulder' at linear density from 5 to $20 \mathrm{kFRPI}$ and high recording density $\mathrm{D}_{50}$ of $105 \mathrm{kFRPI}$ was attained. Since the 'shoulder' was generally observed for the measurement of perpendicular recording media, it was seemed that the recorded magnetization vector $\mathbf{M}$ has perpendicular component as shown in Fig 2.

\subsection{BaM ferrite films}

Figure 6 shows the surface appearance of $\mathrm{BaM}$ ferrite films deposited at partial oxygen gas pressure $\mathrm{P}_{\mathrm{O}_{2}}$ in the range from 0.003 to 3.7 mTorr. Although the films deposited at quite low $\mathrm{P}_{\mathrm{O}_{2}}$ of 0.003 mTorr and below were only composed of spinel phase crystallites and possessed bumpy surface texture due to excessive growth of crystallites, the film deposited at $\mathrm{P}_{\mathrm{O}_{2}}$ of 0.02 mTorr exhibited very smooth surface and seemed to be suitable for high density recording media. However, the film deposited at $\mathrm{P}_{\mathrm{O}_{2}}$ of 0.3 mTorr revealed irregularities at surface and it changed to fiber structure at $\mathrm{P}_{\mathrm{O}_{2}}$ higher than $2.0 \mathrm{mTorr}$.

Figure 7 shows the dependence of $\Delta \theta_{50}$ and $f_{c}$ of $c$-axis orientation on the distance between target and substrate $d_{1-s}$. The values of $\Delta \theta_{50}$ were determined from the rocking curve of (008) plane for BaM crystallites and the value of $f_{c}$ was determined from ordinary $x$-ray diffraction diagram, as proposed by Lotgering[5], where $f_{c}$ of 1.0 corresponds to the complete c-axis orientation and $\mathrm{f}_{c}<1.0$ means that the film includes crystallites with other orientation. The value of $\mathrm{f}_{c}$ increased steeply with increase of $d_{t-s}$ in the range of $35-50 \mathrm{~mm}$ and reached about 1.0 when it is longer than $65 \mathrm{~mm}$ and $\Delta \theta_{50}$ decreased from 10 to $3^{\circ}$ with increase of $d_{t-s}$. It seemed that, since the bombardment of high energy particles, such as $\gamma$-electrons and negative oxygen ions from plasma and the recoiled particles from target surface was suppressed, crystallinity was improved in appropriately low $\mathrm{P}_{\mathrm{O}_{2}}$ and enough long $d_{1-s}$. It was clarified that the suppression of plasma damage to the film surface is intrinsically necessary for the depositon of $\mathrm{BaM}$ ferrite films with good c-axis orientation using a conventional RF diode sputtering apparatus.

Ba ferrite film had almost perpendicular magnetic anisotropy as shown in Fig.8. The read/write characteristics of BaM ferrite disk media were also evaluated without protective and lubricant layers by a $\mathrm{Mn}-\mathrm{Zn}$ ferrite head whose head gap g, track width (a) $\mathrm{P}_{\mathrm{O}_{2}}=0.003$ m'Torr

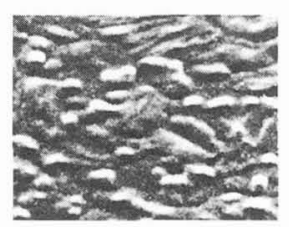

(c) $0.3 \mathrm{mTorr}$

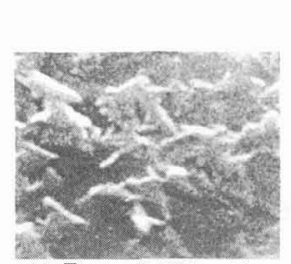

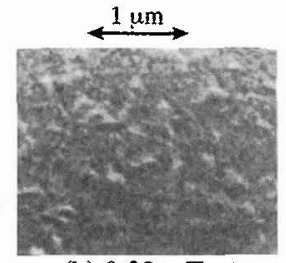

(b) $0.02 \mathrm{~m}$ Torr

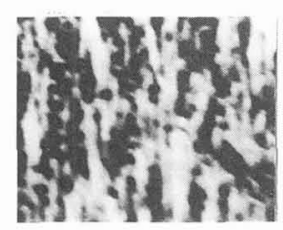

(a) $2.0 \mathrm{~m}$ Torr
Fig.6 SEM photographs of BaM ferrite films deposited at various $\mathrm{P}_{\mathrm{O}_{2}}$.

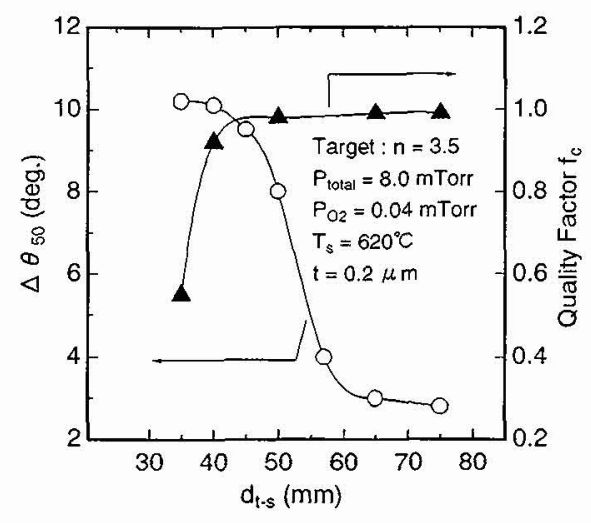

Fig.7 Dependences of $\Delta \theta_{50}$ and $f_{c}$ on $d_{1-s}$. 


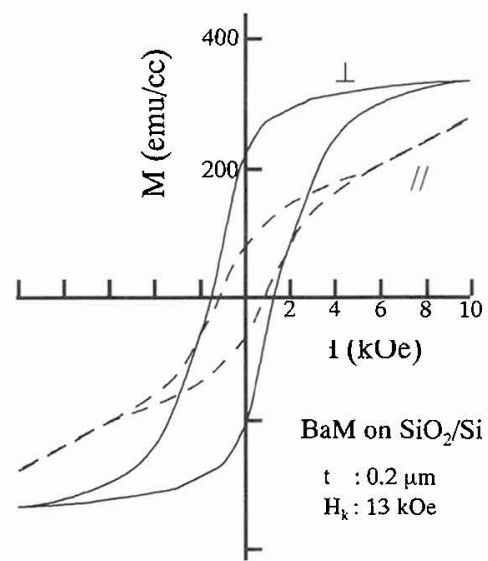

Fig.8 Typical hysteresis loops of BaM ferrite film measured in in-plane and perpendicular directions.

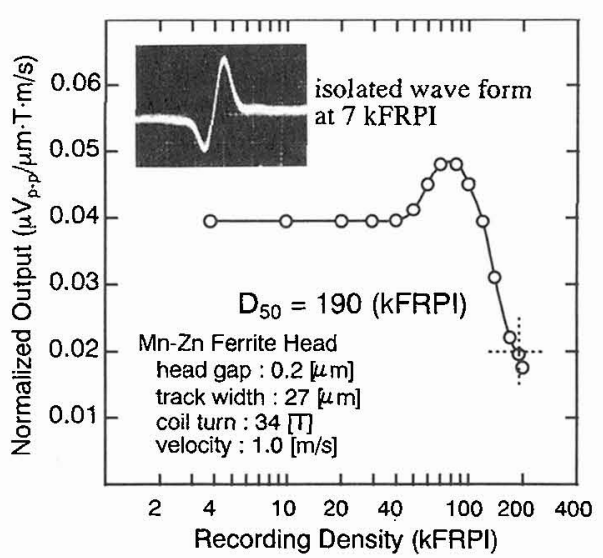

Fig.9 Dependences of output voltage on linear recording density of $\mathrm{BaM}$ ferrite disks and an isolated wave form at $7 \mathrm{kFRPI}$.

and coil turn number were $0.2 \mu \mathrm{m}, 27 \mu \mathrm{m}$ and of $34 \mathrm{turn}$, respectively. The relative velocity was $1.0 \mathrm{~m} / \mathrm{s}$. Very high linear recording density $D_{50}$ of 190 kFRPI was obtained as shown in Fig.9. High dipulse-ratio of 0.65 in isolated wave form at the density of 7 kFRPI and clear 'shoulder' at linear recording density from 50 to $120 \mathrm{kFRPI}$ implied that perpendicular magnetic was successfully performed in the BaM ferrite disk.

\section{CONCLUSION}

Co- $\mathrm{Zn}$ ferrite and $\mathrm{BaM}$ ferrite films were deposited by using a facing targets sputtering(FTS) apparatus and by a conventional RF diode sputtering apparatus, respectively. Their surface texture, crystallographic and magnetic characteristics, and $\mathrm{read} / \mathrm{write}$ characteristics in contact mode were investigated.

$\mathrm{Co}-\mathrm{Zn}$ ferrite films with (111) orientation and BaM ferrite films with excellent c-axis orientation deposited in this study have high potential as the isotropic and perpendicular recording layers, respectively.

Although the $\mathrm{D}_{50}$ of $\mathrm{Co}-\mathrm{Zn}$ ferrite disks and $\mathrm{Ba}$ ferrite disks to date were still lower than that of conventional $\mathrm{Co}-\mathrm{Cr} / \mathrm{Cr}$ disks, it may be possible to increase it by optimizing of the magnetic characteristics of both ferrite films and by the usage of MR head for reading.

\section{REFERENCES}

[1] S. Tsuboi, T. Korenai, N. Ishiwata, K. Yamada and K. Tagami; J. Mag. Soc. Japan, vol. 18, No. S1, pp. 95-98, 1994.

[2] J. U. Lemke; IEEE Trans. on Magn., vol. 15, No. 6, pp. 1561-1563, 1979.

[3]M. Naoe, S. Yamanaka and Y. Hoshi; IEEE Trans. on Magn., vol. 16, No.5, pp.646-648, 1980.

[4]M. Naoe, S. Hasunuma, Y. Hoshi and S. Yamanaka; IEEE Trans. on Magn., vol. 17, No.6, pp.3184-3186, 1981.

[S]F. K. Lotgering; J. Inorg. Nucl. Chem., vol. 9, pp.113-123, 1959. 